\title{
Metamaterial-Based Sub-Microwave Electromagnetic Field Energy Harvesting System
}

\author{
Mikołaj Nowak (iD
}

check for updates

Citation: Nowak, M.

Metamaterial-Based Sub-Microwave Electromagnetic Field Energy Harvesting System. Energies 2021, 14, 3370. https://doi.org/10.3390/ en14123370

Academic Editor: Awadesh Kumar Mallik

Received: 27 April 2021

Accepted: 1 June 2021

Published: 8 June 2021

Publisher's Note: MDPI stays neutral with regard to jurisdictional claims in published maps and institutional affiliations.

Copyright: (C) 2021 by the author. Licensee MDPI, Basel, Switzerland. This article is an open access article distributed under the terms and conditions of the Creative Commons Attribution (CC BY) license (https:/ / creativecommons.org/licenses/by/ $4.0 /)$.
Department of Electrical Engineering, Control Systems and Informatics, Faculty of Electrical and Control Engineering, Gdańsk University of Technology, 80-233 Gdańsk, Poland; mikolaj.nowak@pg.edu.pl

\begin{abstract}
This paper presents the comprehensive analysis of the sub-microwave, radio frequency band resonant metastructures' electromagnetic properties with a particular emphasis on the possibility of their application in energy harvesting systems. Selected structures based on representative topologies of metamaterials have been implemented in the simulation environment. The models have been analyzed and their substitute average electromagnetic parameters (absorption, reflection, transmission and homogenized permeability coefficients) have been determined. On the basis of simulation research, prototypes of electromagnetic field two-dimensional absorbers have been manufactured and verified experimentally in the proposed test system. The absorber has been implemented as a component of the low-cost energy harvesting system with a high-frequency rectifier and a voltage multiplier, obtaining usable DC energy from the electromagnetic field in certain frequency bands. The energy efficiency of the system has been determined and the potential application in energy harvesting technology has been assessed.
\end{abstract}

Keywords: computer simulation; electromagnetic absorption; energy harvesting; metamaterial absorbers

\section{Introduction}

The dynamic development of semiconductor integrated circuit technology, the growing share of wireless powered devices on the industrial and consumer market (in particular in the field of IoT technology, wearable devices and wireless measurement systems) as well as the current pro-ecological policy resulted in the dissemination of electronic devices for which the average demand for electric power does not exceed a single milliwatt. The existing trends in powering these devices are headed towards two directions-improving the efficiency of conventional electricity sources and searching for alternative, renewable sources. The unconventional approach to providing power for devices with low power consumption has resulted in the demand for a new type of technology in which energy is obtained directly from the device's surroundings, known as energy harvesting. The available energy harvesting $(\mathrm{EH})$ solutions are mostly based on commonly used photovoltaic sources.

However, today there is another potential source of energy-the ubiquitous electromagnetic radiation with a frequency band from hundreds of $\mathrm{kHz}$ to tens of $\mathrm{GHz}$ [1], the so-called "electro-smog". The sources of this radiation are very diverse-from intentionally installed radio and telecommunications transmitters to sources whose emission is an undesirable side effect. The available literature presents various methods of recovering electric energy from the electromagnetic field, mostly based on antenna systems [1,2]. The undoubted disadvantages of antennas, however, are their low geometric compactness (small active surface in relation to the occupied volume) and relatively low absorption (the ability to absorb electromagnetic field energy) [3-6].

Therefore, it became necessary to search for other types of absorption systems with a much higher absorption efficiency and better application parameters, i.e., greater geometric compactness, the ability to shape frequency characteristics and easy integration on any 
working surface. A potential solution to the above problems is absorption systems based on resonant metamaterials [7-17], i.e., special electromagnetic structures exhibiting unusual circuit-field properties in certain frequency bands. The miniaturization potential, the possibility of adjusting the geometry of metamaterials to the substrate on which they are to be installed (e.g., a car body, a roof or walls of a building, housing of electronic appliances), much higher absorption, additional beneficial properties and extensive research into the technology [5,8,9,14-27] (mostly in the microwave spectrum) are important factors supporting the development of effective solutions for obtaining energy from the electromagnetic field using metamaterial absorbers. Table 1 shows a brief summary of selected parameters of EH systems based on rectennas and resonant metamaterials presented in the technical literature in order to compare their electromagnetic energy absorption capabilities.

Table 1. The absorption efficiency of selected EH systems based on rectennas and resonant metamaterials—state-of-the-art.

\begin{tabular}{|c|c|c|c|}
\hline Frequency $f$ & $\begin{array}{l}\text { Energy Absorption } \\
\text { Technique }\end{array}$ & $\begin{array}{c}\text { Absorption Efficiency } \\
\eta_{A \max }\end{array}$ & References \\
\hline $2.45 \mathrm{GHz}$ & Rectenna & up to $10 \%$ & [28] \\
\hline $350-550 \mathrm{MHz}$ & Yagi-Uda array & $4.3 \%$ & this work \\
\hline $700-2700 \mathrm{MHz}$ & LPDA array & $14.8 \%$ & this work \\
\hline $1.96 \mathrm{GHz}$ & LP Patch rectenna & $43-54 \%$ & [29] \\
\hline $6-6.4 \mathrm{GHz}$ & Patch antenna array & $17-32 \%$ & {$[9,18,30]$} \\
\hline $5.4-5.6 \mathrm{GHz}$ & Patch antenna array & up to $52 \%$ & [31] \\
\hline 2-18 GHz & 64 elements spiral rectenna & up to $40 \%$ & [32] \\
\hline $5.8 \mathrm{GHz}$ & Patch rectenna & up to $80 \%$ & {$[33]$} \\
\hline $2.45 \mathrm{GHz}$ & Slot Rectenna & over $65 \%$ & {$[34]$} \\
\hline $2.45 \mathrm{GHz}$ & Patch rectenna & up to $82 \%$ & {$[35]$} \\
\hline $1.57 \mathrm{GHz}$ & $\begin{array}{l}\text { NFRP metamaterial- } \\
\text { inspired rectenna }\end{array}$ & up to $85 \%$ & [17] \\
\hline $6.2-21.4 \mathrm{GHz}$ & MM-ring resonator & over $90 \%$ & [16] \\
\hline $2.8-3.3 \mathrm{GHz}$ & MM-ELC resonator & over $93 \%$ & [36] \\
\hline $6.4-7.5 \mathrm{GHz}$ & MM-MTM resonator & $69.5 \%$ & [25] \\
\hline $\begin{array}{c}\text { 3-12 GHz } \\
\text { (selectively) }\end{array}$ & $\begin{array}{l}\text { MM-Multilayer } \\
\text { SRR resonator }\end{array}$ & over $80 \%$ & {$[24]$} \\
\hline$\sim 900 \mathrm{MHz}$ & MM-SRR resonator & over $78 \%$ & [23] \\
\hline $4.5-7.5 \mathrm{GHz}$ & MM-SRR resonator & $80 \%$ & {$[9,18,30]$} \\
\hline $5.25-6 \mathrm{GHz}$ & MM-GCSRR resonator & up to $92 \%$ & [31] \\
\hline 300-850 MHz & MM-SRR resonatormatrices & up to $91 \%$ & this work \\
\hline
\end{tabular}

The above-mentioned comparison suggests that the absorption systems based on resonance metamaterials have the efficiency of EM field energy absorption by at least several dozen percent higher than in the case of commonly used patch antennas and as much as several times greater than the conventional dipole-type antenna arrays. At the same time, it is worth noting that the efficiency of electromagnetic field energy absorption by antenna systems is inversely proportional to the bandwidth of the antenna and drastically decreases in the case of broadband antennas due to the reduction in the system quality factor $Q$. Metamaterial absorbers make it possible to expand the absorption bandwidth with a much smaller relative decrease in the absorption efficiency.

\subsection{Electromagnetic Smog-Based Energy Harvesting}

The available power of electromagnetic smog in modern urban and industrial environments allows it to effectively power many electronic devices whose power demand is not high $[21,28,29,37]$, as shown in Figure 1. 


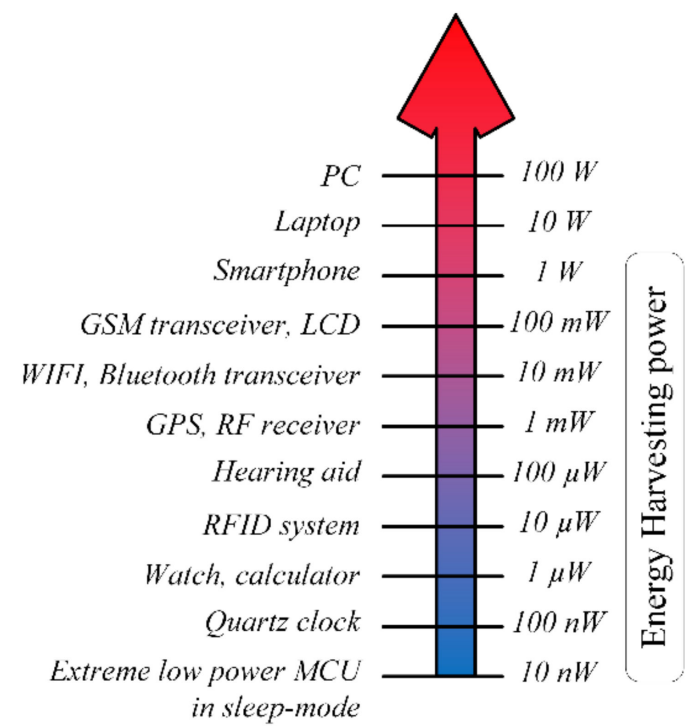

Figure 1. Illustrative graphics of modern electronic devices' power requirements.

In order to verify the energy potential and determine the most advantageous frequency bands for EH purposes, research of the average (for the period of $10 \mathrm{~min}$ ) spectral power density available in a residential area (urban environment) and an industrialized district of Gdańsk city (Poland) has been performed. Measurements have been made using the D-DOT type wideband field probe and verified with a set of omnidirectional antennas with specific properties at a $50 \Omega$ load. The results are presented in Figures 2 and 3.

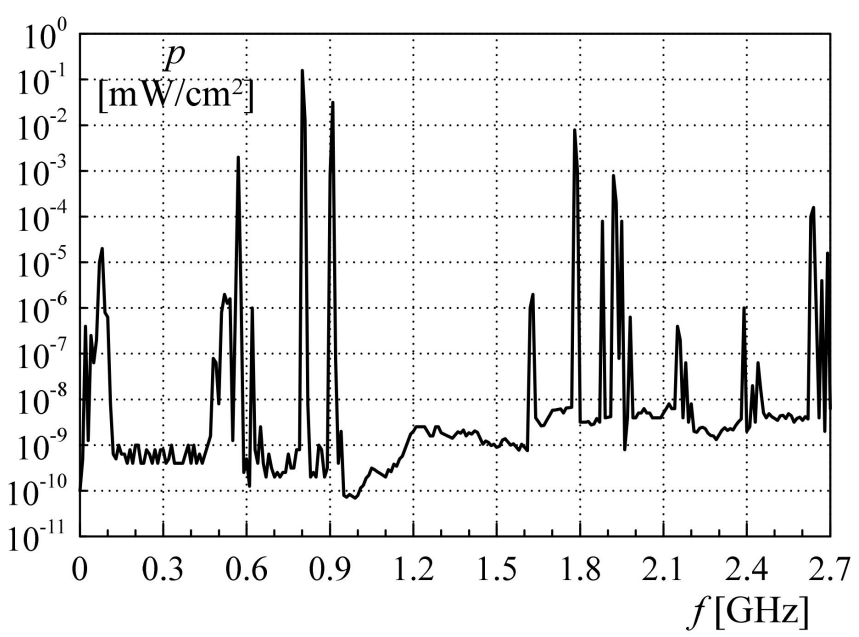

Figure 2. Characteristics of the electromagnetic smog spectral power density in the $9 \mathrm{kHz}$ to $2.7 \mathrm{GHz}$ band in an urban environment-Gdańsk city, Poland.

Based on the supplementary research results, it can be concluded that there are narrow frequency bands, mainly used for telecommunication purposes, where significant levels of power density are available. However, due to the significant dependence of the frequency bands with the greatest availability of power density on the location of the measuring point, the designed energy absorbers should be oriented to a specific application. Hence, for the purposes of this study, several frequency ranges have been arbitrarily designated for which further research has been carried out. 


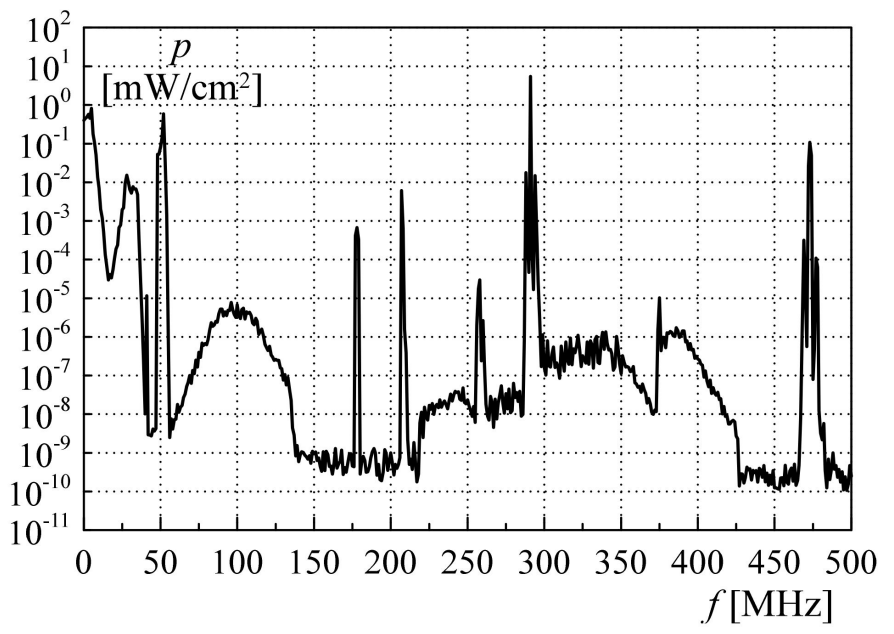

Figure 3. Characteristics of the electromagnetic smog spectral power density in the $9 \mathrm{kHz}$ to $500 \mathrm{MHz}$ band in an industrial environment-Gdańsk city, Poland.

In the industrial environment with a significant concentration of various types of telecommunications transmitters and sources of radiated electromagnetic interference (in the frequency range below approx. $30 \mathrm{MHz}$ ), a significant local increase in the available power density is visible. Due to the similarity of the characteristics of the given environments in the frequency range above $500 \mathrm{MHz}$, the scale of Figure 3 has been adjusted accordingly.

This paper presents the results of studies on metamaterial absorber solutions designed to work in the sub-microwave, radio frequency spectrum for which there is a significant potential for energy harvesting, as indicated by environmental measurements. The proposed concept in terms of the energy absorption efficiency, the possibility of the selective formation of frequency characteristics and the application potential significantly exceeds $\mathrm{EH}$ systems based on conventional antenna arrays.

\subsection{Selected Metamaterial Structures}

Due to the manufacturing technology and macroscopic properties, metamaterial types can be divided into resonant and non-resonant. Resonant metamaterials are mainly metallic structures placed in a dielectric environment in which characteristic dimension $L$ meets the relationship $L<\lambda / 4[38,39]$, where $\lambda$ is the incident wavelength. This condition guarantees that their properties do not only result from the influence of the incident electromagnetic wave but the influence of the secondary wave generated by the resonance of unit cell currents emulating the atomic resonances of the crystal lattice. In the case of non-resonant metamaterials, their characteristic dimension $L$ is much smaller and it is assumed $[38,40,41]$ that it meets the relationship $L<\left(10^{-4}\right.$ to $\left.10^{-6}\right) \lambda$. The properties of such materials are similar; however, they arise due to the presence of other (microscopic) interactions. This paper focuses on the resonant metamaterials only, due to their higher efficiency $[38,40,42]$ in the considered sub-microwave frequency band, as well as the ease of prototyping such structures for experimental purposes.

The paper presents the result of research on the most representative structure, well described in the literature, with a relatively narrow frequency band, but with a high absorption capability $[24,25]$, i.e., the split ring resonator (SRR) cell proposed originally by $[43,44]$. The selection of the resonator unit cell topology was based on a review of the literature, and the decisive factor was the possibility of shaping a narrowband, selective absorption characteristic in the low RF range while maintaining the high geometric compactness of the structures. For comparison, the electric component unit cells (ELC) are characterized by much higher resonance frequencies for the same dimensions as for SRR [7,36], while spiral-type [40] cells, which (for comparable cell sizes) exhibit a lower resonance frequency, have a much larger surface filling which makes it impossible to cover 
transparent surfaces (e.g., windows) with metamaterial matrices. SRR cells represent a compromise between low resonance frequency and high geometry compactness. In the literature, there are examples of the use of SRR cells for EH purposes [16,30,31], but with an emphasis on microwave frequencies (and higher). In this work, models with an absorption band adapted to sub-microwave radio frequencies have been developed, and the geometric and simplified equivalent circuit models are presented in Figure 4 . The equivalent circuit model complexity results from the adopted geometrical dimensions of the resonator unit cell, conductive and dielectric materials' parameters and the required accuracy of model representation. It is possible to design multi-mode cells with many resonance frequencies or with more diffused frequency characteristics. The number of resonator modes strictly depends on its electrical dimensions and the coupling between the conducting paths due to the presence of several resonances between the elements of the metamaterial cell (as shown in the equivalent diagram in Figure $4 \mathrm{~b}$ ) with shifted natural frequency points. In this work, the goal was to construct, as far as possible, single-mode metastructure matrices in order to narrow the selective absorption band.

(a)

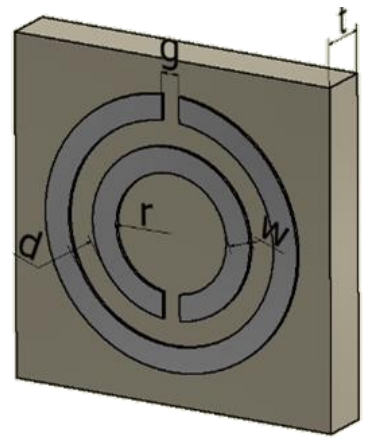

(b)

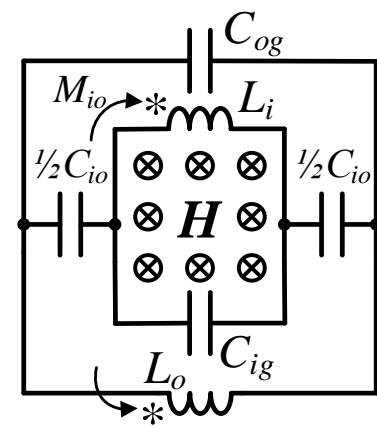

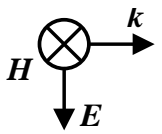

Figure 4. Magnetic split ring resonator unit cell (a) geometric model, and (b) simplified resonance circuit model with the optimal incident wave polarization condition: $C_{o g}$-outer ring gap capacitance, $C_{i g}$-inner ring gap capacitance, $C_{i o}$-inner to outer ring traces capacitance, $L_{i}$-inner ring selfinductance, $L_{0}$-outer ring self-inductance, $M_{i o}$-inner to outer ring mutual inductance.

\section{Metamaterial Structure Simulation Research}

The purpose of the selected resonant metamaterials' simulation tests is determining their electromagnetic properties in the frequency domain, as well as the suitability of the presented structures for the process of high frequency electromagnetic field energy absorption. Resonators have been modeled in the form of copper tracks with a thickness of $50 \mu \mathrm{m}$ on a FR-4 (glass-epoxy) dielectric laminate with a thickness of $1.6 \mathrm{~mm}$. The losses of both conductive and dielectric materials have been taken into account in the simulation model. The initial dimensions of the investigated resonator unit cell have been determined on the basis of analytical relationships [5,42], in order to adjust them to an arbitrarily selected frequency of approx. $250 \mathrm{MHz}(\mathrm{VHF})$. The geometric dimensions specified in Figure $4 \mathrm{a}$ are presented in Table 2.

Table 2. Dimensions of the SRR resonator with a natural frequency of approx. $250 \mathrm{MHz}$.

\begin{tabular}{ccc}
\hline Symbol & Parameter & Value \\
\hline$g$ & ring air gap & $0.6 \mathrm{~mm}$ \\
$w$ & conductive path width & $1 \mathrm{~mm}$ \\
$r$ & smaller ring inner radius & $17.4 \mathrm{~mm}$ \\
$d$ & distance between the rings & $2 \mathrm{~mm}$ \\
$a$ & unit cell size & $44.8 \mathrm{~mm}$ \\
$t$ & laminate thickness & $1.6 \mathrm{~mm}$ \\
$h$ & conductive layer thickness & $50 \mu \mathrm{m}$ \\
\hline
\end{tabular}


Geometric models of elementary SRR cells implemented in the CST Studio [45] computing environment and created finite element meshes are shown in Figure 5. As can be seen, metastructure unit cells tuned to the lower radio frequency range may show a small percentage of the coverage of the dielectric substrate with an opaque conducting material (due to the use of narrow path thickness $\mathrm{w}$ and a small inter-ring distance d). Therefore, it is possible to apply such structures on transparent functional surfaces, such as windows, without a significant reduction in visibility.

(a)

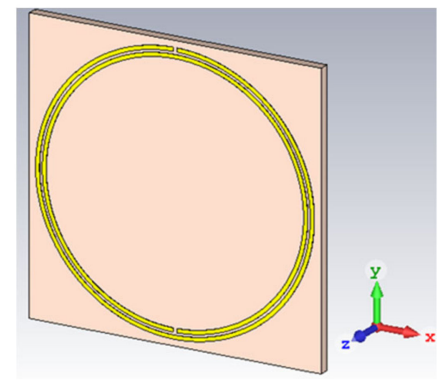

(b)

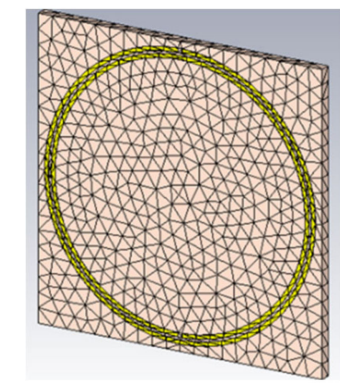

Figure 5. View of (a) the geometric model of the SRR unit cell and (b) typical created mesh of finite elements.

In accordance with the purpose of the research, two-dimensional matrices consisting of unit cells of the SRR resonator have been created (Figure 6).

(a)

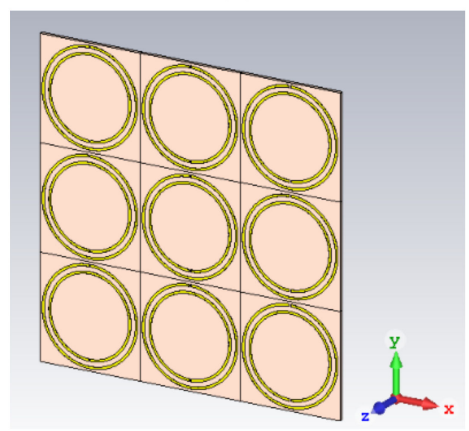

(b)

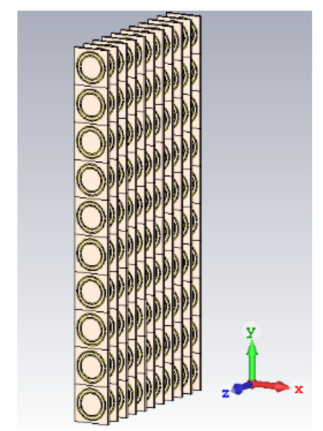

Figure 6. View of (a) SRR two-dimensional planar matrix and (b) SRR two-dimensional transverse matrix.

It should be noted that the resonant frequency of the resonator arrays in comparison to a single unit cell (consisting of the same unit cells) is different due to the interaction (mainly capacitive) between the individual matrix cells. For instance, a matrix composed of cells with a natural frequency of about $250 \mathrm{MHz}$ shows a resonance around $350 \mathrm{MHz}$. This phenomenon can be minimized by increasing the distance between unit cells within one matrix; however, due to the aim to maximize the matrix density, and thus increase the efficiency of electromagnetic field energy absorption, this procedure has been neglected in the further prototyping process. It is also possible to tune matrices' natural frequency by changing the geometrical dimensions of the unit cells (Figure 4a).

For simulation purposes, two representative resonant frequencies have been selected, i.e., $350 \mathrm{MHz}$ (for planar SSR matrix) and $850 \mathrm{MHz}$ (for transverse SSR matrix). The scaled dimensions of the SRR matrices have been calculated and are summarized in Table 3 . The simulation models presented in this paper do not take into account the connections between the matrix unit cells, which has a certain impact on the correlation of the parameters of simulation models and real prototypes of metastructure matrices. However, due to the 
use of some design steps when arranging the strip connections on the actual prototypes of the matrices related to the minimization of parasitic parameters, these discrepancies have been reduced.

Table 3. Dimensions of frequency-scaled SRR matrices.

\begin{tabular}{|c|c|c|c|}
\hline \multirow{2}{*}{ Symbol } & \multirow{2}{*}{ Parameter } & \multicolumn{2}{|c|}{ Value } \\
\hline & & $350 \mathrm{MHz}$ & $850 \mathrm{MHz}$ \\
\hline$g$ & ring air gap & $0.6 \mathrm{~mm}$ & $1.2 \mathrm{~mm}$ \\
\hline$w$ & conductive path width & $1 \mathrm{~mm}$ & $0.8 \mathrm{~mm}$ \\
\hline$r$ & smaller ring inner radius & $17.4 \mathrm{~mm}$ & $7 \mathrm{~mm}$ \\
\hline$d$ & distance between the rings & $2 \mathrm{~mm}$ & $1.6 \mathrm{~mm}$ \\
\hline$a$ & unit cell size & $44.8 \mathrm{~mm}$ & $21 \mathrm{~mm}$ \\
\hline$t$ & laminate thickness & $1.6 \mathrm{~mm}$ & $1.6 \mathrm{~mm}$ \\
\hline$h$ & conductive layer thickness & $50 \mu \mathrm{m}$ & $50 \mu \mathrm{m}$ \\
\hline
\end{tabular}

A series of full-wave parameter calculations as a function of the incident wave frequency have been performed. In each case, the systems were excited by a plane wave with appropriate polarization and a constant power density of $100 \mathrm{~mW} / \mathrm{cm}^{2}$, e.g., the $350 \mathrm{MHz}$ SSR unit cell was stimulated with a power of $1.78 \mathrm{~W}$. The generation of the discrete finite element mesh has been carried out by adopting first-degree tetrahedral elements. The maximum size of the finite elements for the resonator models has been chosen experimentally, based on the criterion of the minimum increase in computational accuracy with each subsequent step of refining the model mesh. In the case of the space surrounding the resonators, the criterion of minimizing the number of nodes has been used due to the lack of significant influence of this area on the calculation results. In both cases, the necessary condition (resulting from the maximum ratio of the single finite element characteristic size $\gamma$ to the smallest incident wavelength $\lambda$ ) in Equation (1) has been applied.

$$
\gamma \leq \frac{\lambda_{\min }}{10}
$$

The models use boundary conditions appropriate for the propagation path of the electromagnetic wave in the waveguide. The direction of wave propagation has been determined on the basis of the polarization condition of the metamaterial cell incident wave.

On the basis of simulations, frequency characteristics of quantitative parameters characterizing selected structures, i.e., absorbance $A$, reflectance $R$, and transmittance $T$, have been plotted (Figure 7). At the same time, thermal losses in copper and dielectric material at the resonance point of a single SRR cell were determined at the level of approx. $3 \%$ of the absorbed power.

In Figure 7c, the presence of multiple absorbance peaks in the SRR two-dimensional transverse matrix can be noticed. This phenomenon results from the existence of a mutual shift of the resonance frequencies of individual stripes constituting the absorption structure. The inner strips of the structure interact more noticeably with the adjacent ones than the outer strips of the matrix. This fact makes it possible to shape the matrix absorption bandwidth at the cost of a decrease in the absorption efficiency ( $Q$ factor) of the system. Illustrative views of the electric field distribution around the elementary SRR cell at the resonance point and out of resonance are shown in Figure 8. 
(a)

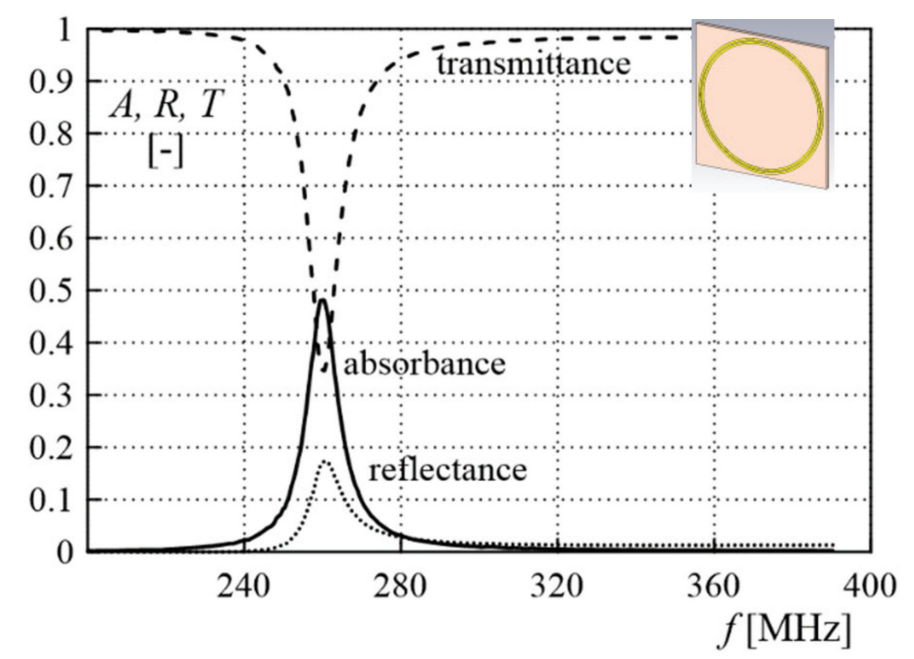

(b)

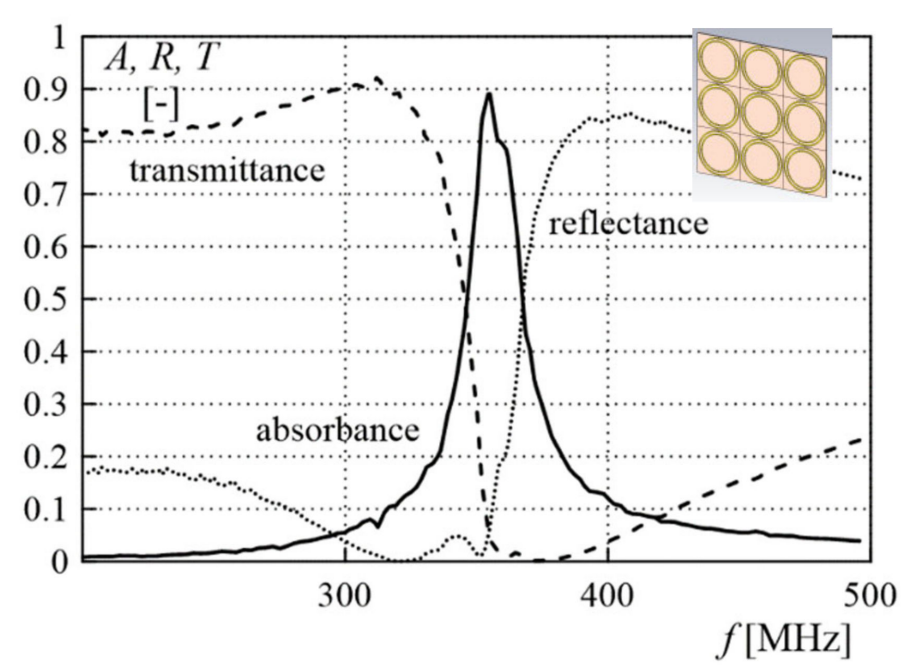

(c)

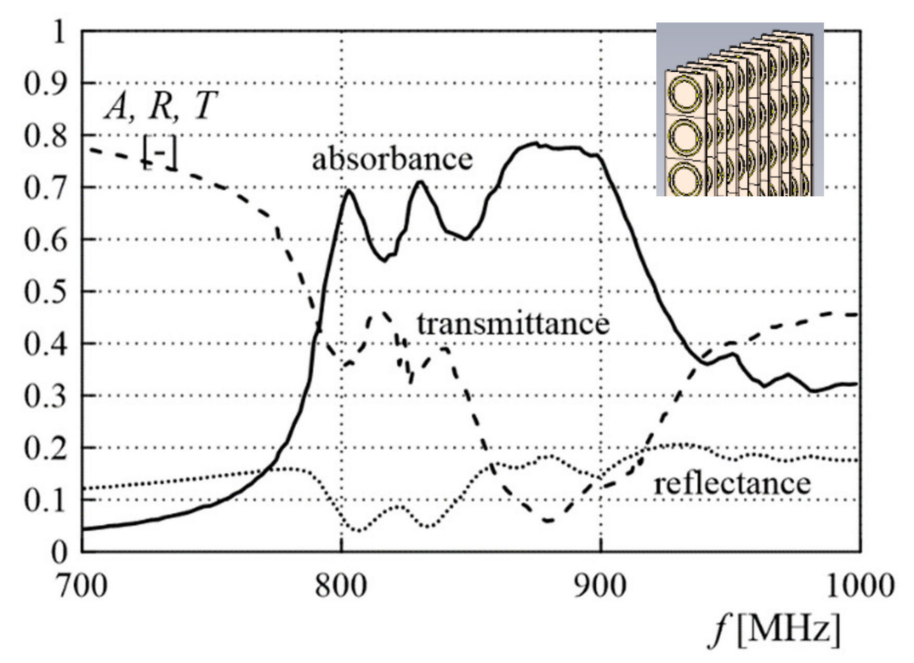

Figure 7. Frequency characteristics of absorbance A, reflectance $\mathrm{R}$ and transmittance coefficients of (a) a single SRR unit cell $\left(f_{0}=260 \mathrm{MHz}\right)$, (b) a flat two-dimensional SRR matrix $\left(f_{0}=355 \mathrm{MHz}\right)$, and (c) a transverse two-dimensional SRR matrix $\left(f_{0}=850 \mathrm{MHz}\right)$. 
(a)

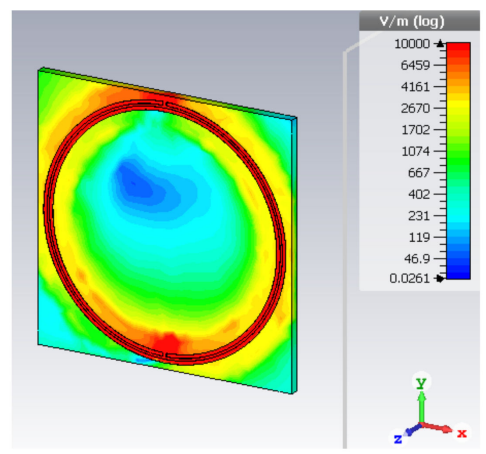

(b)

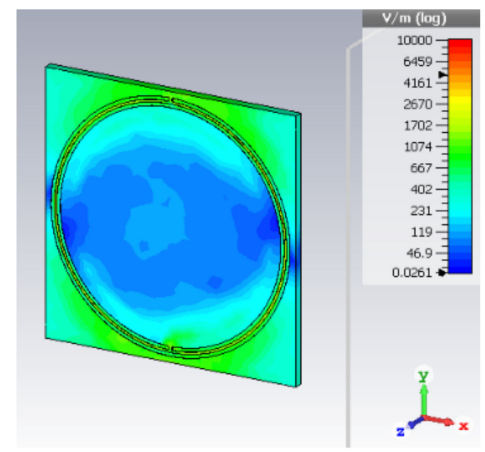

Figure 8. View of the electric field strength module distribution near the SRR unit cell for (a) resonance frequency, and (b) out of resonance frequency.

For the SRR in resonance, there is a significant concentration of electromagnetic field components in the inter-ring region and at rings' split points. Hence, the highest efficiency in draining electrical energy from the resonator can be expected when the leads are connected precisely at the split point [24].

The characteristics of relative complex permeability coefficients of selected structures (Figure 9) for the representative frequency bands (in which the resonance of metamaterial cells is visible) have been determined using the appropriate simplified transformation algorithm using Matlab [46]. In the literature, there are various approaches to the metamaterials' permeability and permittivity extraction algorithms [19,47-50] that differ in the level of complexity and physical interpretation. However, the discussion on the physical interpretation of the $\mu$ and $\varepsilon$ parameters is not the subject of this application-oriented paper. The key output parameters of the computer simulation are the coefficients $A, R$ and $T$, which were determined on the basis of the full-wave power balance in a waveguide.

(a)

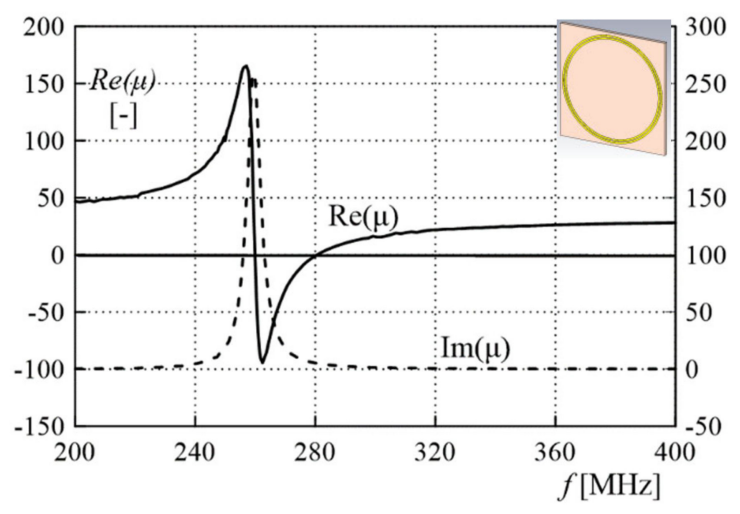

(b)

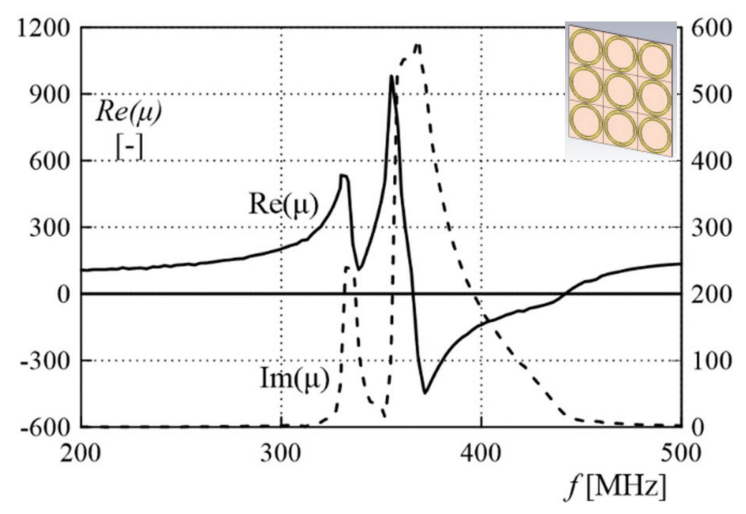

Figure 9. Cont. 
(c)

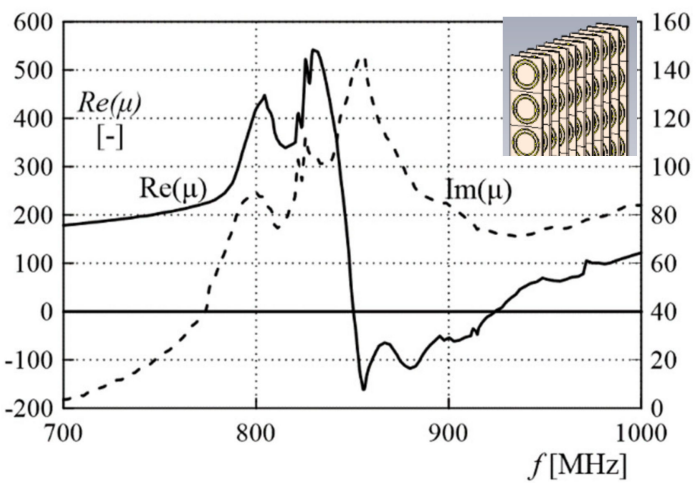

Figure 9. Frequency characteristics of the relative complex (a) unit cell SRR permeability coefficient, (b) flat two dimensional SRR matrix $\left(f_{0}=355 \mathrm{MHz}\right)$ permeability coefficient, and (c) a transverse two-dimensional SRR matrix $\left(f_{0}=850 \mathrm{MHz}\right)$ permeability coefficient.

In order to optimize the impedance matching of the load and metamaterial absorber, the output impedance characteristics of matrices around the resonant point have also been determined. An example of the transverse matrix output impedance $Z_{\text {out }}$ characteristics is shown in Figure 10.

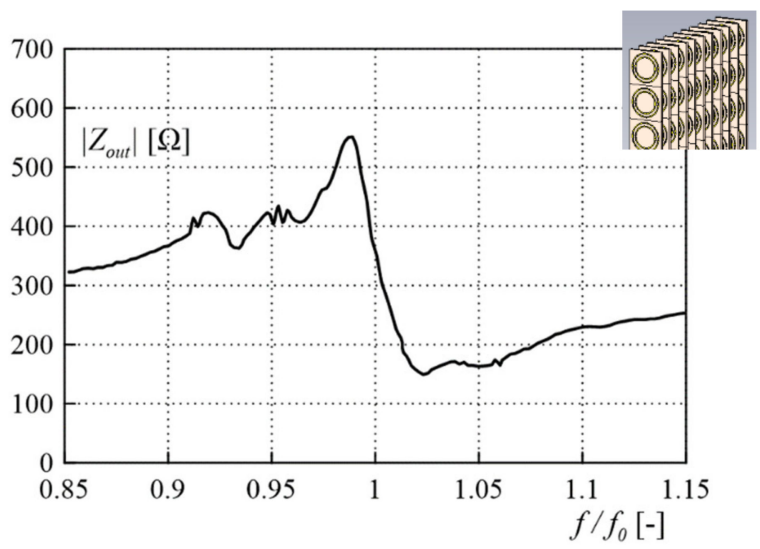

Figure 10. Frequency characteristics of the output impedance of a transverse two-dimensional SRR $\operatorname{matrix}\left(f_{0}=850 \mathrm{MHz}\right)$.

\section{Experimental Studies of Metamaterial Structures}

For the final verification of metamaterial structures' quantitative parameters and to assess their suitability for use as energy absorbers for electromagnetic field energy harvesting, the prototypes of metamaterial matrices have been designed, manufactured and tested. The aim of the experimental tests was to determine the absorption and transmission coefficients of the metamaterial matrices and compare them to conventional antenna systems. The following assumptions have been made:

- The experimental research aims to compare the absorption properties of metamaterial matrices with conventional antenna arrays and verifies the suitability of the metasurfaces for energy harvesting purposes.

- External interferences and electromagnetic signals present in the test space have a negligible influence on the measurement results due to the significant level of power emitted by the transmitting antenna.

- The influence of electromagnetic wave reflections in the test space on the measurement results has been ignored. 


\subsection{Materials and Methods}

Due to the wide frequency band for which the measurements have been performed (200 MHz to $1500 \mathrm{MHz}$ ), two topologies of directional, high-gain transceiving antennas, i.e., the Yagi-Uda ( $350 \mathrm{MHz}$ to $550 \mathrm{MHz}$ band, with $\mathrm{G}=13 \mathrm{dBi}$ directional gain) and the broadband log-periodic antenna LPDA (700 MHz to $2700 \mathrm{MHz}$, with $\mathrm{G}=12 \mathrm{dBi}$ directional gain), were used.

In order to determine the absorption characteristics of antenna systems, a symmetrical arrangement resulting directly from the reciprocity principle was used. This system requires a uniform structure of the transmitting and receiving antenna.

The source antennas and energy receivers (in the form of receiving antennas and metamaterial absorbers) were placed with a constant distance of $\mathrm{x}=2 \mathrm{~m}$, which is approximately minimum distance ensuring the location of EM energy receivers in the far zone of the transmitting antenna (in order to ensure the specified, most optimal polarization of the wave incident on the metamaterial matrix, as shown in Figure 4), determined on the basis of the phase criterion [3] and at a constant height of $\mathrm{h}=1.5 \mathrm{~m}$ on insulating support to eliminate the ground influence on the path of wave propagation. The tests were performed in a laboratory space equipped with shielding systems limiting the influence of external interferences on the measurement results.

About $10 \mathrm{~W}$ of power was fed to the transmitting antenna from the broadband RF amplifier. The Rohde \& Schwarz SMA100B RF signal generator was used as the signal source. Based on VSWR measurements of the transmitting system, the percentage value of the power transmitted by the antenna was determined as not less than $96.8 \%$ of the supplied power. With the use of a broadband D-DOT (SFE3-5G by Montena Technology) probe, the additional measurements of the available surface power density at the location of the receiving systems were performed and determined at the average level of $\mathrm{S}_{\text {ref }}=82.2 \mu \mathrm{W} / \mathrm{cm}^{2}$ (for Yagi-Uda as a transmitter), and $\mathrm{S}_{\text {ref }}=74.3 \mu \mathrm{W} / \mathrm{cm}^{2}$ (for LPDA). The Rohde \& Schwarz FSVA3004 spectrum analyzer was used as an energy receiver and power level measuring system.

The drawing of the test system for measuring the absorption properties of classical antennas is presented in Figure 11.

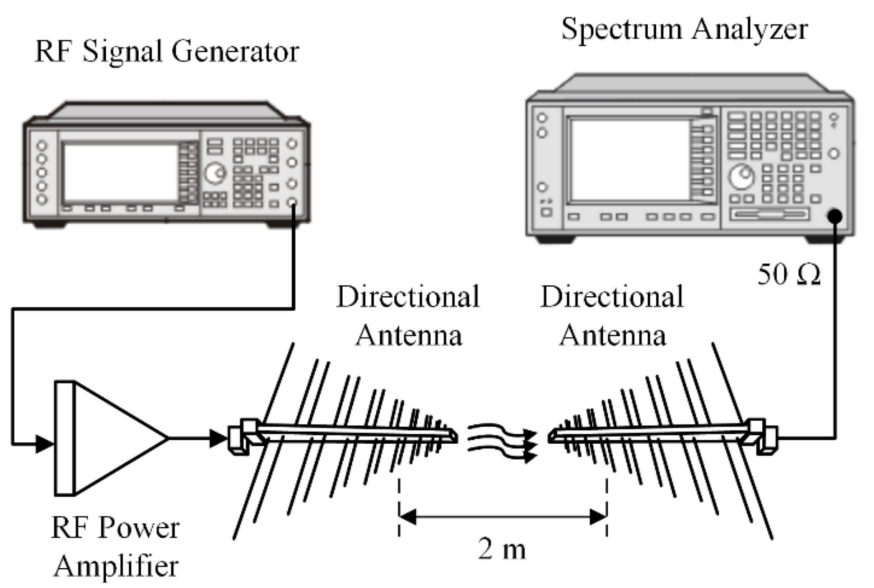

Figure 11. Schematic diagram of the test system for measuring the absorption properties of classical antennas.

The drawing of the test system for measuring the metamaterial matrices' absorbed power characteristics is shown in Figure 12. 


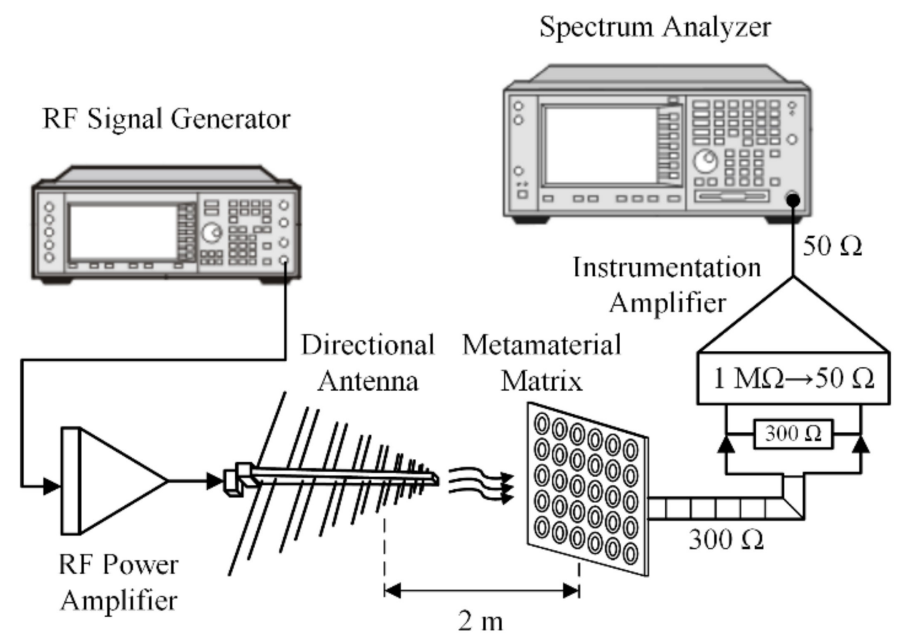

Figure 12. Schematic diagram of the test system for measuring the absorption properties of metamaterial absorbers.

The use of wideband antennas with an impedance of $50 \Omega$ as energy receivers guaranteed the input of the signal receiver impedance matching. H-1000 coaxial cables with a minimized attenuation coefficient were used as the connecting lines. In the case of metamaterial absorbers, the value of the load impedance, matched most acceptably to all tested matrices, can be defined as the geometric mean value of the output impedance of individual structures. This value was estimated at $Z_{L}=353 \Omega$ on the basis of simulation results. Following the above, in order to connect the matrices with the load, it is unacceptable to use coaxial cables with an impedance of $50 \Omega$ or $75 \Omega$. Therefore, a cable with the closest impedance value was used, i.e., a symmetrical flat antenna cable with an impedance of $300 \Omega$. Additionally, in order to load the transmission line properly, an instrumentation amplifier (adapter) with an input impedance of $1 \mathrm{M} \Omega$ and an output impedance of $50 \Omega$ was used, the input of which was terminated with a non-inductive $300 \Omega$ resistor. The load mismatch attenuation coefficient was calculated as $0.7 \%$, which is a satisfactory value.

The two-dimensional flat matrices' effective area was assumed as $256 \mathrm{~cm}^{2}$, which corresponds to a square with a side length of $16 \mathrm{~cm}$. Flat matrices were manufactured in three variants of resonance frequencies, i.e., $332 \mathrm{MHz}, 425 \mathrm{MHz}$, and $505 \mathrm{MHz}$. The transverse matrix was designed for a resonant frequency of approx. $816 \mathrm{MHz}$ and made as a four-layer package, with the dimensions of each layer around $20 \mathrm{~cm}$ long by $4 \mathrm{~cm}$ wide and a distance between the layers of $1.5 \mathrm{~cm}$. According to the observation of the highest concentration of the electromagnetic field in the split points of the SRR, unit cells were connected to the matrix at this point. Individual cells within one matrix were connected in series and parallel, while the outputs from the matrices were made in the form of high-frequency coaxial connectors. Connections between unit cells were designed as wide strips of copper to minimize the parasitic inductances. The printed circuit boards were made as double-sided and the connections on the bottom layer were shifted with respect to the connections on the top layer of the board in order to minimize parasitic capacitances. In order to increase the thickness of the printed paths to the level of about $50 \mu \mathrm{m}$, tin electroplating was used. The views of the metamaterial matrices prototypes are shown in Figure 13. 
(a)

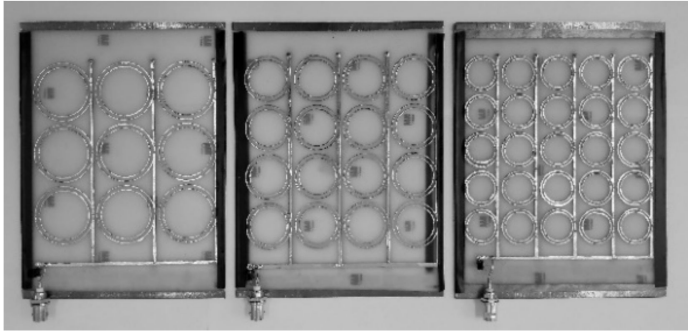

(b)

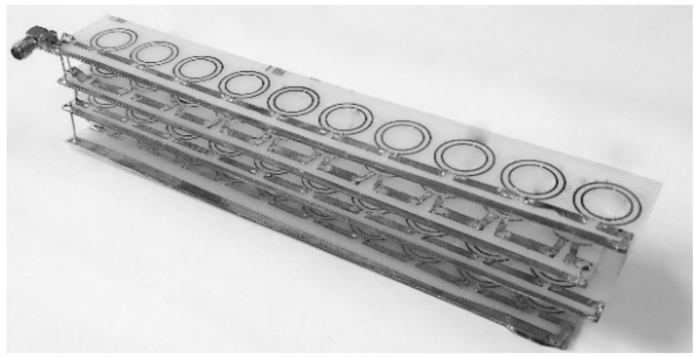

Figure 13. View of the prototypes of the (a) three frequency variants of a flat metamaterial matrix, and (b) transverse metamaterial matrix.

\subsection{Experimental Results of the System Absorption Efficiency}

In order to compare the efficiency of electromagnetic field energy absorption by conventional antenna systems and metamaterial absorbers in the radio frequency range, the frequency characteristics of the receiver power have been measured in the test system as shown in Figures 11 and 12. The experimental results have been presented in the form of relative power absorption efficiency characteristics of the considered systems, which have been defined as (Equation (2)):

$$
\eta=\frac{P_{A}}{A_{e f f} S_{r e f}}
$$

where: $P_{A}$-power absorbed by the system $[\mu \mathrm{W}], A_{\text {eff }}$ effective surface area of the absorption system $\left[\mathrm{cm}^{2}\right], S_{r e f}$-reference available surface power density at the location of the absorbing system $\left[\mu \mathrm{W} / \mathrm{cm}^{2}\right]$.

The effective absorption areas $A_{\text {eff }}$ of the Yagi-Uda and LPDA antennas have also been determined based on the approximate relationship (Equation (3)), i.e., $2618 \mathrm{~cm}^{2}$ and 560 $\mathrm{cm}^{2}$, respectively. The effective surface of metamaterial absorbers used for calculations was the real surface of the prepared matrices.

$$
A_{e f f} \approx \frac{G c^{2}}{4 \pi f^{2}}
$$

where: $G$-antenna gain for frequency $\mathrm{f}[-], c$ - speed of light $[\mathrm{m} / \mathrm{s}], f$-center frequency of the antenna $[\mathrm{Hz}]$.

Figure 14 presents the frequency characteristics of the electromagnetic field energy absorption efficiency of conventional antenna systems used as energy receivers along with the maximum value of absorbed power and the determined maximum efficiency. Figure 15 presents the frequency characteristics of the efficiency of electromagnetic field energy absorption in the presented metamaterial matrices along with the maximum value of absorbed power and determined maximum efficiency at the resonance point. 
(a)

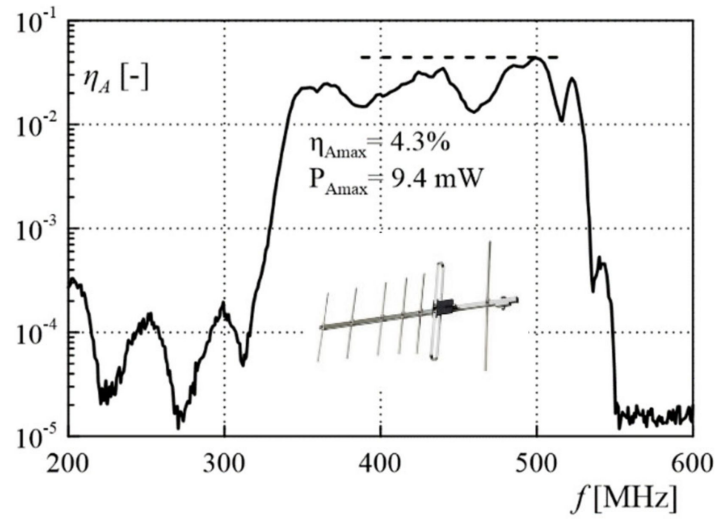

(b)

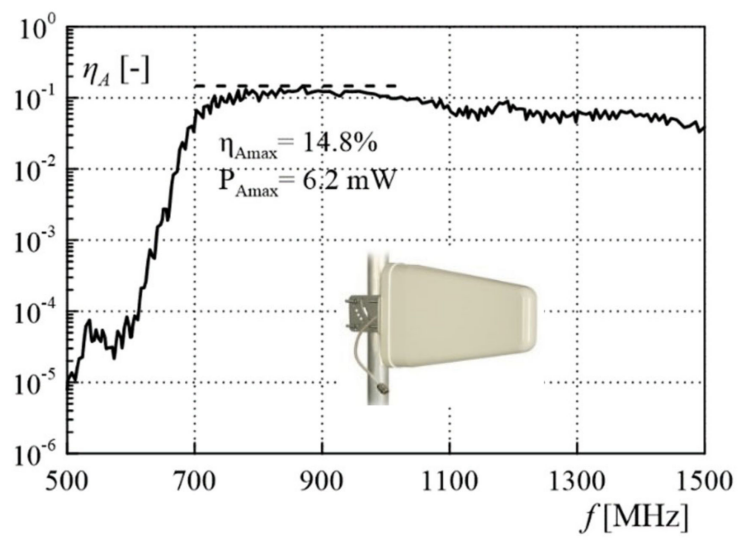

Figure 14. The relative power absorption efficiency frequency characteristics of the conventional antenna systems (a) Yagi-Uda and (b) LPDA.

(a)

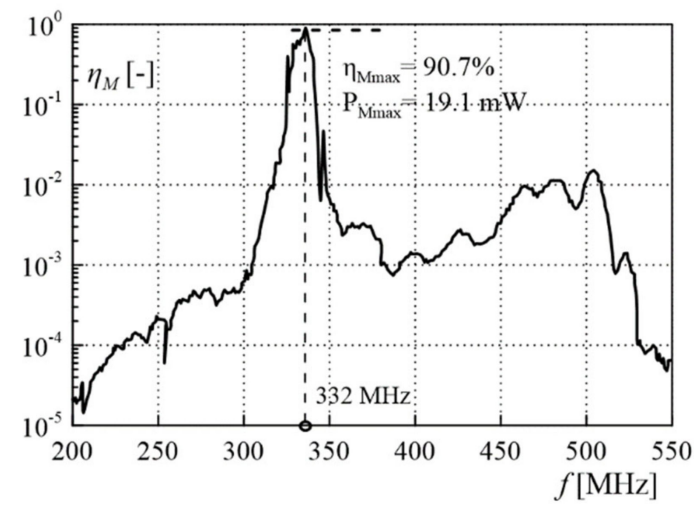

(b)

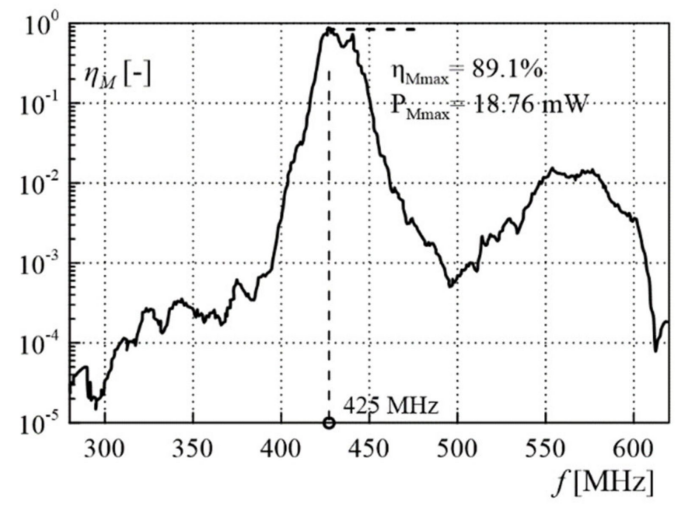

Figure 15. Cont. 
(c)

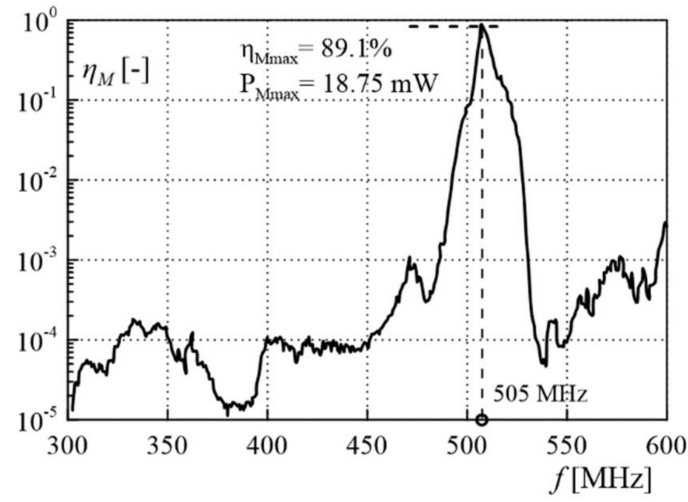

(d)

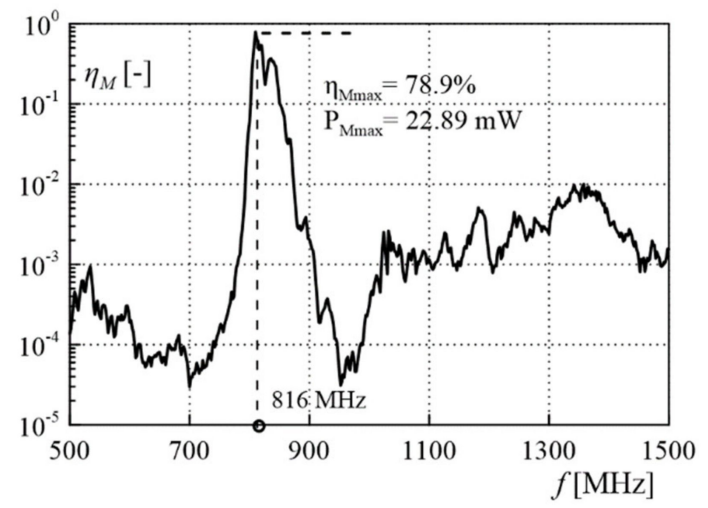

Figure 15. The relative power absorption efficiency characteristics of the metamaterial absorber matrices: (a) flat two-dimensional SRR ( $\left.f_{0}=332 \mathrm{MHz}\right)$, (b) flat two-dimensional SRR $\left(f_{0}=425 \mathrm{MHz}\right)$, (c) flat two-dimensional SRR $\left(f_{0}=505 \mathrm{MHz}\right),(\mathrm{d})$ transverse two-dimensional SRR $\left(f_{0}=816 \mathrm{MHz}\right)$.

Characteristic parameters of the tested absorption systems are shown in Table 4.

Table 4. Comparison of tested systems' absorption parameters.

\begin{tabular}{ccccccc}
\hline \multirow{2}{*}{ Parameter } & \multicolumn{5}{c}{ Value } \\
\cline { 2 - 7 } & SRR Flat & SRR Flat & SRR Flat & SRR Transv. & Yagi-Uda & LPDA \\
\hline Resonant frequency $f_{0}[\mathrm{MHz}]$ & 332 & 425 & 505 & 816 & - \\
Bandwidth $(-3 \mathrm{~dB}) \gamma[\mathrm{MHz}]$ & 11 & 17 & 19 & 18 & $350-550$ & $700-2700$ \\
Effective absorption surface $A_{\text {eff }}\left[\mathrm{cm}^{2}\right]$ & 256 & 256 & 256 & 320 & 2618 & 560 \\
Max. absorbed power $P_{A \max }[\mathrm{mW}]$ & 19.1 & 18.7 & 18.7 & 22.89 & 9.4 & 6.2 \\
Relative absorption efficiency $\eta_{\max }[\%]$ & 90.7 & 89.1 & 89.1 & 78.9 & 4.3 & 14.8 \\
\hline
\end{tabular}

The proposed topology of resonators is characterized by very narrow resonance bands, which makes it possible to design systems with high absorption for frequency ranges not useful for the powered device (e.g., electromagnetic interference) without the absorption of useful signals (e.g., communication). To shape the selectivity of the absorbers, a layered combination of two-dimensional flat matrices has been proposed, where for each layer it is possible to use an absorber with a different resonance frequency to cover the desired absorption band. The measurement results of this type of solution are shown in Figure 16. As predicted, the frequency response is a superposition of the three individual metamaterial matrices. The peak value of the power absorbed decreased to the value of $15.7 \mathrm{~mW}$, which in terms of percentage absorption efficiency is $75.1 \%$. The visible decrease in the efficiency of energy absorption due to the interactions between individual matrices has been found. Another possibility of shaping the frequency characteristics of metamaterial absorbers is to use the multi-mode structure topologies [39], e.g., based on fractal geometries. However, 
due to the resonant quality factor $\mathrm{Q}$ reduction in these types of solutions, their absorption efficiency reaches lower values.

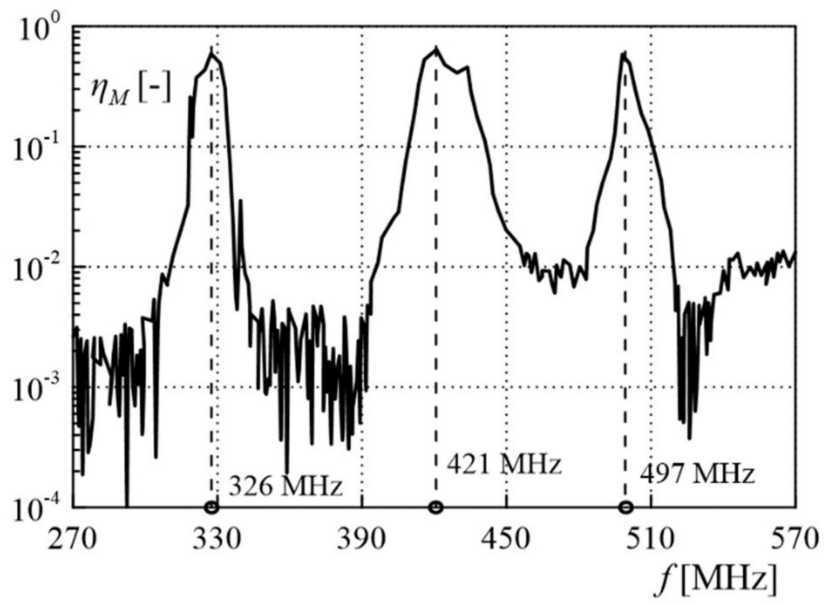

Figure 16. The relative power absorption efficiency characteristics of the combined metamaterial absorber matrices.

\section{Metamaterials in the Energy Harvesting System}

In order to verify the suitability of metamaterial absorbers for energy harvesting purposes, a prototype of a system for converting energy from a high-frequency electromagnetic field to usable DC has been developed. Due to the low output voltages of the metamaterial absorbers, a symmetrical rectifier with a voltage multiplier has been used. The presented $\mathrm{EH}$ system has been tested in the test configuration shown in Figure 17 to determine the frequency characteristics, energy conversion efficiency and variability of output parameters as a function of load.

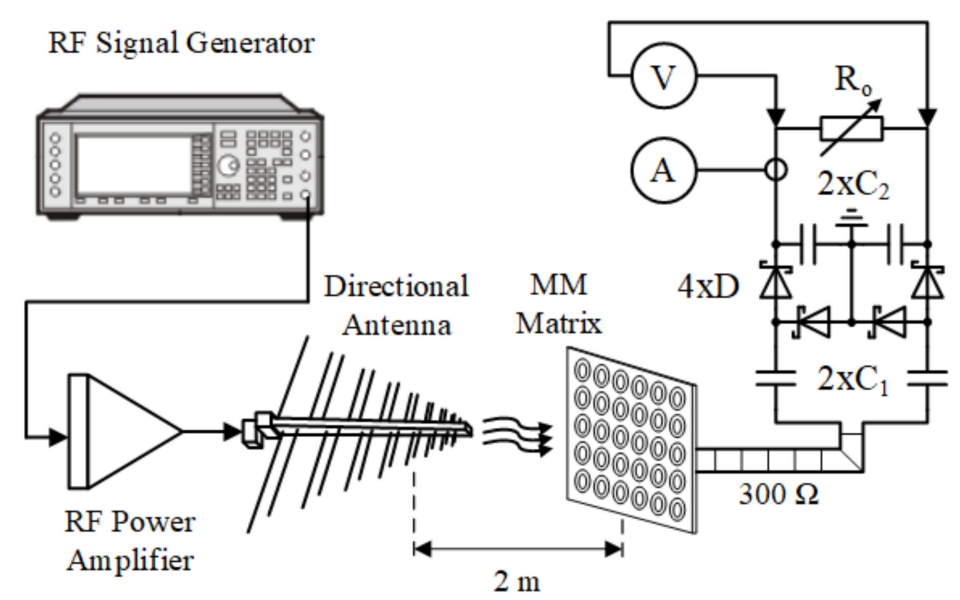

Figure 17. Schematic diagram of the test system for the metamaterial absorbers' EH suitability assessment.

The rectifier circuit has been built with the use of high-frequency Schottky diodes BAT15-04R and ceramic capacitors with capacitance values $C_{1}=1 \mathrm{nF}$ and $C_{2}=10 \mathrm{nF}$, reduced ESR, and increased tolerance of $0.2 \%$. In order to determine the characteristics of the output voltage and the power generated by the system as a function of the load, the values of the load resistance $R_{o}$ were changed in the range from $2 \mathrm{k} \Omega$ to $16 \mathrm{k} \Omega$ for the first resonant frequency (Figure 16) of the absorber. Based on the load characteristics, the optimal value of the load resistance has been determined at the level of $5.6 \mathrm{k} \Omega$. For the optimal value of the load resistance of the system, the voltage and the output power value 
of the EH system as a function of the frequency of the input signal have been measured. The measurement results are presented in Figures 18 and 19.

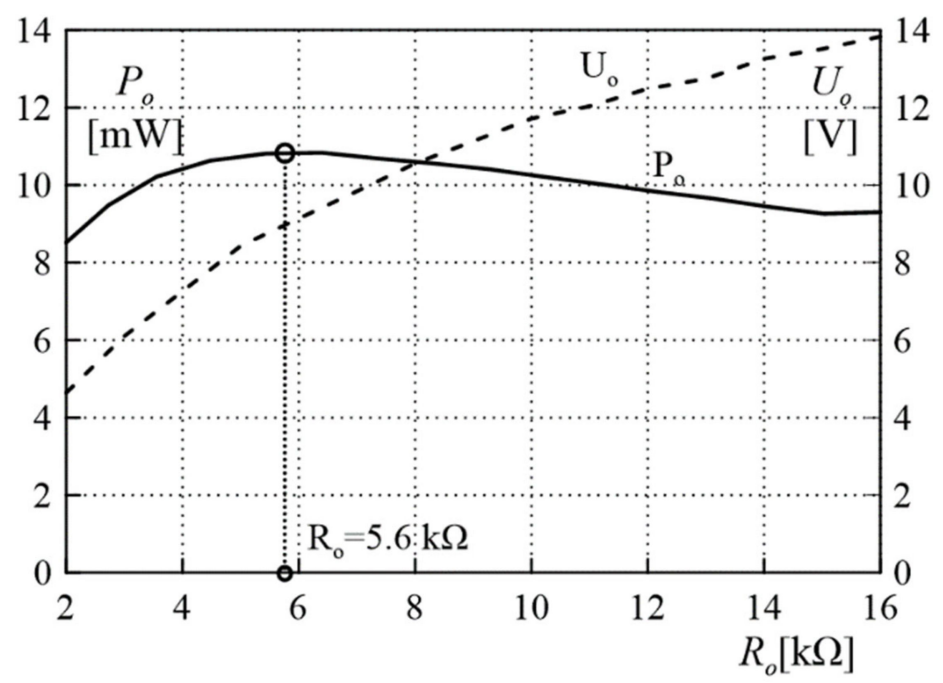

Figure 18. The output power $P_{o}$ and voltage $U_{o}$ generated by proposed $\mathrm{EH}$ system as a function of load resistance for the first resonance frequency $\left(f_{0}=332 \mathrm{MHz}\right)$.

(a)

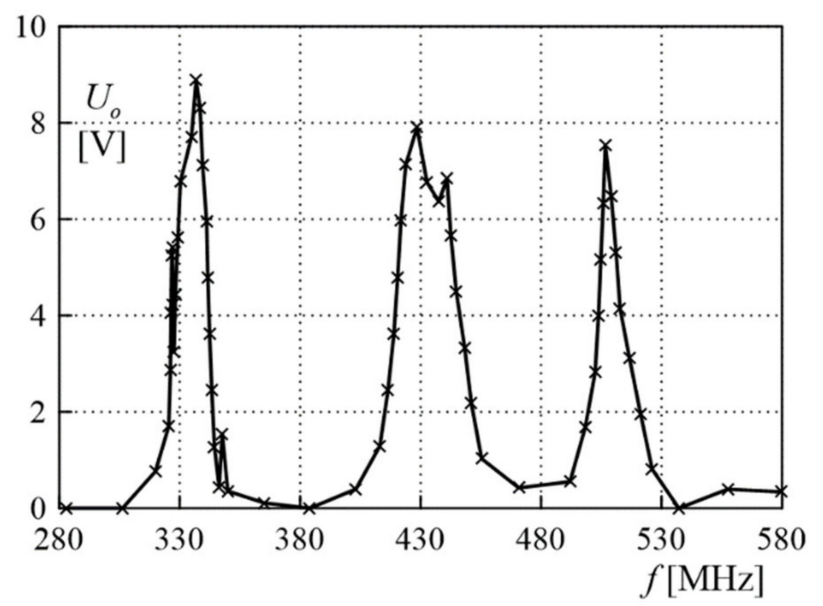

(b)

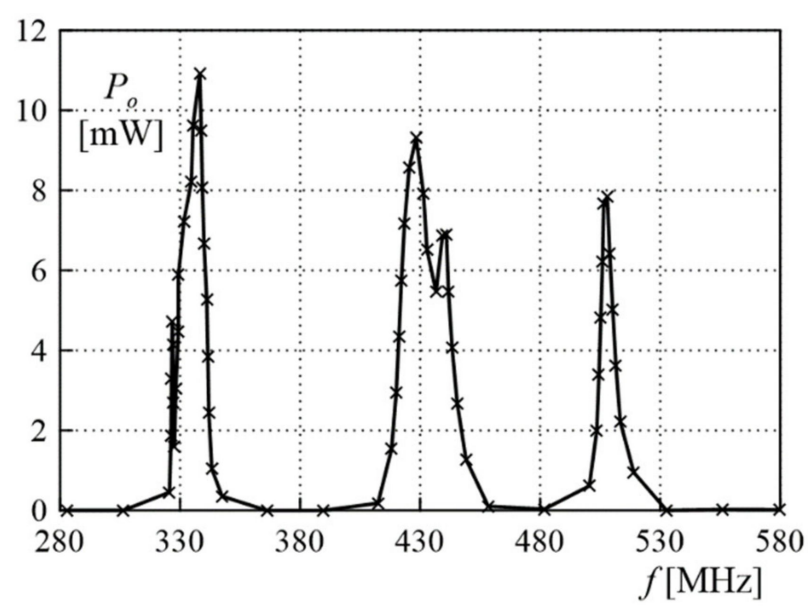

Figure 19. Frequency characteristics of (a) the output voltage, and (b) the output power of the EH system loaded with the optimal resistance value. 
The maximum value of the obtained power has been determined at the level of approx. $10.9 \mathrm{~mW}$ at a voltage of $9.1 \mathrm{~V}$. Assuming the available power density from the transmitting antenna, the maximum value of energy conversion efficiency of the entire EH system has been calculated at the level of approx. 56\% for the frequency of $332 \mathrm{MHz}$. The high efficiency drop of the EH system is caused by the adopted low-cost rectifier with a voltage multiplier circuit. A further increase in the system efficiency is possible through the use of low-loss switching power electronic elements, made, for example, of gallium nitride.

\section{Conclusions}

Based on the conducted research, it has been proven that high-frequency electromagnetic field energy absorbers based on resonance metamaterials constitute a competitive alternative to conventional antenna systems (with comparable sizes) as transducers in $\mathrm{EH}$ systems achieving efficiency exceeding 90\% (more than five times higher than the conventional dipole-type antenna arrays). It should also be noted that extending the absorption band in the case of antenna systems comes at the significant expense of the maximum absorption efficiency. Metamaterial absorbers are more resistant to this phenomenon.

Effective shaping of the metamaterials' energy absorption frequency bands can be achieved by the superposition of many matrices with different resonance frequencies. This type of solution allows the formation of the absorption band of the EH system selectively. The absorption band can also be formed through the use of multi-mode metamaterial absorbers, e.g., fractal-based structures.

The proposed EH system with a metamaterial absorber and a symmetrical rectifier with a voltage multiplier meets the desired expectations. The efficiency of energy transmission to the receiver or potential energy storage, taking into account losses at each stage of energy conversion, reaches the value of approximately $56 \%$ and is at a satisfactory level, comparable or greater than the effectiveness of solutions available in the literature. It is possible to further increase the efficiency of the system by using a rectifier and a voltage multiplier with lower switching losses.

The practical application of meta-surface structures is easier compared to classic antenna systems due to the greater flexibility in the geometry selection of the two-dimensional matrices. Many types of surfaces can be covered with metamaterial absorbers, including housings of electronic devices. Metamaterial absorbers, due to the possibility of selectively shaping the frequency absorption characteristics, will not attenuate the telecommunications signals necessary for the proper operation of devices. In particular, in the case of narrowstrip resonators such as the SRR (especially for the radio and microwave frequency range), it is possible to coat transparent utility surfaces such as glass car windows or residential windows with metastructures without a significant reduction in visibility. The proposed application enables powering electronic systems with low-power demand using only the energy harvesting technique or in cooperation with other energy sources. It should be noted, however, that due to the availability of sufficient electromagnetic field power only in the environments with a high level of electromagnetic field intensity, the use of this type of technology is so far limited mainly to urban and industrial environments.

Resonant metamaterials can also be used as high-efficiency couplers and receivers in the microwave wireless power transfer technique with the additional possibility of directing the electromagnetic radiation beam (metamaterial lenses) or highly effective and selective electromagnetic shielding systems for electromagnetic compatibility or military purposes.

Funding: This research received no external funding.

Institutional Review Board Statement: Not applicable.

Informed Consent Statement: Not applicable.

Conflicts of Interest: The author declares no conflict of interest. 


\section{References}

1. Valenta, C.R.; Durgin, G.D. Harvesting Wireless Power: Survey of Energy-Harvester Conversion Efficiency in Far-Field, Wireless Power Transfer Systems. IEEE Microw. Mag. 2014, 15, 108-120. [CrossRef]

2. Wagih, M.; Weddell, A.S.; Beeby, S. Rectennas for radio-frequency energy harvesting and wireless power transfer: A review of antenna design [antenna applications corner]. IEEE Antennas Propag. Magazine. 2020, 62, 95-107. [CrossRef]

3. Andersen, J.; Frandsen, A. Absorption efficiency of receiving antennas. IEEE Trans. Antennas Propag. 2005, 53, 2843-2889. [CrossRef]

4. Gustafsson, M.; Cismasu, M.; Nordebo, S. Absorption Efficiency and Physical Bounds on Antennas. Int. J. Antennas Propag. 2010, 2010, 1-7. [CrossRef]

5. Mahamuni, C.V. Performance enhancement of microstrip patch antenna using metamaterial cover. In Proceedings of the 2016 International Conference on Global Trends in Signal Processing, Information Computing and Communication (ICGTSPICC), Jalgaon, India, 22-24 December 2016; pp. 382-388.

6. Wheeler, H. Fundamental Limitations of Small Antennas. Proc. IRE 1947, 35, 1479-1484. [CrossRef]

7. Odabasi, H.; Teixeira, F.L.; Güney, D.Ö. Electrically small, complementary electric-field-coupled resonator antennas. J. Appl. Phys. 2013, 113, 84903. [CrossRef]

8. Pranav, U.; Sudheesh, S.; Stanly, P.; Sankar, S.; Devika, R.; Pradeep, A. Metamaterial Based Energy Harvester. Proc. Comput. Sci. 2016, 93, 74-80. [CrossRef]

9. Ramahi, O.M.; Almoneef, T.S.; Alshareef, M.; Boybay, M.S. Metamaterial particles for electromagnetic energy harvesting. Appl. Phys. Lett. 2012, 101. [CrossRef]

10. Ridge, K.; Engineering, C. Left-handed materials with broad bandwidth and low loss using double resonant frequency structure. IEEE Antennas Propag. Soc. Symp. 2004, 3792-3795.

11. Smith, D.R.; Pendry, J.B.; Wiltshire, M.C.K. Metamaterials and Negative Refractive Index. Science 2004, 305, 788-792. [CrossRef]

12. Smith, D.R.; Kroll, N. Negative Refractive Index in Left-Handed Materials. Phys. Rev. Lett. 2000, 85, 2933-2936. [CrossRef]

13. Veselago, V.G. The Electrodynamics of Substances with Simultaneously Negative Values of $\epsilon$ and $\mu$. Phys. Uspekhi. 1968, 10, 509-514. [CrossRef]

14. Watts, C.M.; Liu, X.; Padilla, W.J. Metamaterial Electromagnetic Wave Absorbers. Adv. Mater. 2012, 24, OP98-OP120. [CrossRef]

15. Wu, Q.; Meng, F.-Y.; Wu, M.-F.; Wu, J.; Li, L.-W. Research on the Negative Permittivity Effect of the Thin Wires Array in Left-Handed Material by Transmission Line Theory. PIERS Online 2005, 1, 196-200. [CrossRef]

16. Zhong, H.-T.; Yang, X.-X.; Song, X.-T.; Guo, Z.-Y.; Yu, F. Wideband metamaterial array with polarization-independent and wide incident angle for harvesting ambient electromagnetic energy and wireless power transfer. Appl. Phys. Lett. 2017, 111, 213902. [CrossRef]

17. Zhu, N.; Ziolkowski, R.W.; Xin, H. A metamaterial-inspired, electrically small rectenna for high-efficiency, low power harvesting and scavenging at the global positioning system L1 frequency. Appl. Phys. Lett. 2011, 99, 114101. [CrossRef]

18. Almoneef, T.S.; Ramahi, O.M. Harvesting electromagnetic energy using metamaterial particles. In Proceedings of the 2013 IEEE Antennas and Propagation Society International Symposium (APSURSI), Orlando, FL, USA, 7-13 July 2013; pp. $1046-1047$.

19. Alù, A. First-principles homogenization theory for periodic metamaterials. Phys. Rev. B 2011, 84, 1-18. [CrossRef]

20. Cheng, Y.Z.; Fang, C.; Zhang, Z.; Wang, B.; Chen, J.; Gong, R.Z. A compact and polarization-insensitive perfect metamaterial absorber for electromagnetic energy harvesting application. Electromagn. Res. Symp. (PIERS) 2016, 1, 8-11.

21. Falkenstein, E.; Costinett, D.; Zane, R.; Popovic, Z. Far-Field RF-Powered Variable Duty Cycle Wireless Sensor Platform. IEEE Trans. Circuits Syst. II Express Briefs 2011, 58, 822-826. [CrossRef]

22. Duan, X.; Chen, X.; Zhou, L. A metamaterial harvester with integrated rectifying functionality. In Proceedings of the 2016 IEEE/ACES International Conference on Wireless Information Technology and Systems (ICWITS) and Applied Computational Electromagnetics (ACES), Honolulu, HI, USA, 13-18 March 2016; pp. 1-2. [CrossRef]

23. Hawkes, A.M.; Katko, A.R.; Cummer, S.A. A microwave metamaterial with integrated power harvesting functionality. Appl. Phys. Lett. 2013, 103, 1-3. [CrossRef]

24. Karaaslan, M.; Bağmanc1, M.; Ünal, E.; Akgol, O.; Sabah, C. Microwave energy harvesting based on metamaterial absorbers with multi-layered square split rings for wireless communications. Opt. Commun. 2017, 392, 31-38. [CrossRef]

25. Khan, S.; Eibert, T.F. A multi-resonant meta-absorber as an electromagnetic energy harvester. In Proceedings of the 2017 IEEE International Symposium on Antennas and Propagation \& USNC/URSI National Radio Science Meeting, San Diego, CA, USA, 9-14 July 2017; pp. 1091-1092. [CrossRef]

26. Landy, N.I.; Sajuyigbe, S.; Mock, J.J.; Smith, D.R.; Padilla, W.J. Perfect Metamaterial Absorber. Phys. Rev. Lett. 2008, 100, 207402. [CrossRef] [PubMed]

27. Ziolkowski, R.W.; Erentok, A. Metamaterial-based efficient electrically small antennas. IEEE Trans. Antennas Propag. 2006, 54, 2113-2130. [CrossRef]

28. Paing, T.; Morroni, J.; Dolgov, A.; Shin, J.; Brannan, J.; Zane, R.; Popovic, Z. Wirelessly-Powered Wireless Sensor Platform. In Proceedings of the 2007 European Conference on Wireless Technologies, Munich, Germany, 9-12 October 2007; pp. 241-244.

29. Falkenstein, E.; Roberg, M.; Popovic, Z. Low-Power Wireless Power Delivery. IEEE Trans. Microw. Theory Tech. 2012, 60, $2277-2286$. [CrossRef] 
30. Almoneef, T.; Ramahi, O.M. Split-ring resonator arrays for electromagnetic energy harvesting. Prog. Electromagn. Res. B 2015, 62, 167-180. [CrossRef]

31. Alavikia, B.; Almoneef, T.S.; Ramahi, O.M. Complementary split ring resonator arrays for electromagnetic energy harvesting. Appl. Phys. Lett. 2015, 107, 1-6. [CrossRef]

32. Hagerty, J.; Helmbrecht, F.; McCalpin, W.; Zane, R.; Popovic, Z. Recycling Ambient Microwave Energy With Broad-Band Rectenna Arrays. IEEE Trans. Microw. Theory Tech. 2004, 52, 1014-1024. [CrossRef]

33. Duy, P.N.; Ha-Van, N.; Seo, C. A Design of 5.8 GHz Rectenna Array for Wireless Energy Harvesting Applications. In Proceedings of the 2020 IEEE Wireless Power Transfer Conference (WPTC), Seoul, Korea, 15-19 November 2020; pp. 87-90.

34. Vera, G.A.; Georgiadis, A.; Collado, A.; Via, S. Design of a $2.45 \mathrm{GHz}$ rectenna for electromagnetic (EM) energy scavenging. In Proceedings of the 2010 IEEE Radio and Wireless Symposium (RWS), New Orleans, LA, USA, 10-14 January 2010.

35. Takhedmit, H.; Merabet, B.; Cirio, L.; Allard, B.; Costa, F.; Vollaire, C.; Picon, O. A 2.45-GHz low cost and efficient rectenna. In Proceedings of the Fourth European Conference on Antennas and Propagation, Barcelona, Spain, 12-16 April 2010.

36. Almoneef, T.S.; Ramahi, O.M. Metamaterial electromagnetic energy harvester with near unity efficiency. Appl. Phys. Lett. 2015, 106, 153902. [CrossRef]

37. Svensson, C.; Liu, D. Low Power Circuit Techniques. Low Power Des. Methodol. 1996, 336, 37-64.

38. Capolino, F. Theory and Phenomena of Metamaterials; CRC Press: Boca Raton, FL, USA, 2017.

39. Engheta, N.; Ziolkowski, R.W. Metamaterials: Physics and Engineering Explorations; John Wiley \& Sons, Inc.: Hoboken, NJ, USA, 2006.

40. Chen, W.; Bingham, C.M.; Mak, K.M.; Caira, N.W.; Padilla, W.J. Extremely subwavelength planar magnetic metamaterials. Phys. Rev. B 2012, 85, 1-5. [CrossRef]

41. Eleftheriades, G.; Balmain, K. Nagative-Refraction Metamaterials; John Wiley \& Sons, Inc.: Hoboken, NJ, USA, 2005.

42. Naqui, J. Fundamentals of Planar Metamaterials and Subwavelength Resonators. In Springer Theses; Springer Science and Business Media LLC: Heidelberg/Berlin, Germany, 2016; pp. 5-43.

43. Pendry, J.B.; Holden, A.J.; Robbins, D.J.; Stewart, W.J. Magnetism from conductors and enhanced nonlinear phenomena. IEEE Trans. Microw. Theory Tech. 1999, 47, 2075-2084. [CrossRef]

44. Smith, S.G.L.; Davis, A.M.J. The split ring resonator. Proc. R. Soc. A Math. Phys. Eng. Sci. 2010, 466, 3117-3134. [CrossRef]

45. CST Studio 2018. Available online: www.3ds.com/products-services/simulia/products/cst-studio-suite (accessed on 6 June 2021).

46. Numan, A.B.; Sharawi, M.S. Extraction of Material Parameters for Metamaterials Using a Full-Wave Simulator [Education Column]. IEEE Antennas Propag. Mag. 2013, 55, 202-211. [CrossRef]

47. Chen, X.; Grzegorczyk, T.M.; Wu, B.; Pacheco, J.; Kong, J.A. Robust method to retrieve the constitutive effective parameters of metamaterials. Phys. Rev. E 2004, 70, 1-7. [CrossRef]

48. Hindy, M.A.; Elsagheer, R.M.; Yasseen, M.S. Experimental retrieval of the negative parameters 'permittivity and permeability' based on a circular split ring resonator (CSRR) left handed metamaterial. J. Electr. Syst. Inf. Technol. 2018, 5, 208-215. [CrossRef]

49. Smith, D.R.; Vier, D.C.; Koschny, T.; Soukoulis, C.M. Electromagnetic parameter retrieval from inhomogeneous metamaterials. Phys. Rev. E 2005, 71, 036617. [CrossRef]

50. Chen, Z.; Guo, B.; Yang, Y.; Cheng, C. Metamaterials-based enhanced energy harvesting: A review. Phys. B Condens. Matter 2014, 438, 1-8. [CrossRef] 